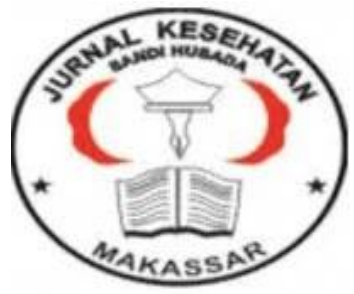

\author{
Jurnal Ilmiah Kesehatan Sandi Husada \\ hhttps://akper-sandikarsa.e-journal.id/JIKSH \\ Vol 9, No, 1, Juni 2020, pp; 8-12 \\ p-ISSN: 2354-6093 dan e-ISSN: 2654-4563 \\ DOI: $10.35816 /$ jiskh.v10i2.197
}

\title{
Uji Validitas Angket SLCQ-I pada Mahasiswa Fakultas Kedokteran Universitas Malahayati Lampung
}

Validity Test of SLCQ-I Questionnaire on

Medical Students of Malahayati University, Lampung

\author{
Ahmad Zidane Sagareno', Sutarto ${ }^{2}$ \\ ${ }_{1}^{1}$ Pendidikan Dokter, Fakultas Kedokteran, Universitas Lampung \\ ${ }^{2}$ Bagian IKKOM dan Ilmu Kesehatan Masyarakat
}

\begin{abstract}
Artikel info
Artikel history:

Received; 26 Januari 2020

Revised; 26 Januari 2020

Accepted; 26 Januari 2020

Abstract

The learning process requires concentration in order to achieve the expected learning outcomes. Data from the measurement results of learning concentration will certainly be useful in evaluating learning. The availability of limited questionnaire makes research on the concentration of learning difficult to do on bachelor student. Therefore a valid questionnaire is needed to collect data. The aims of study is to conduct a validity test of learning concentration questionnaire on bachelor student. The method used in validity test is observational analytic with cross sectional approach. The statistical test used is the Pearson Product Moment correlation and the reliability test with internal consistency. The results obtained for all items in the questionnaire validity test above 0.3 and the reliability test questionnaire value Cronbach alpha 0.924. The conclusion is SLCQ-I (Student Learning Concentration Questionnaire Indonesia Version) fulfills the validity and reliability requirements so it is declared valid and reliable.
\end{abstract}

\begin{abstract}
Abstrak.
Proses belajar membutuhkan konsentrasi agar mencapai hasil belajar yang diharapkan. Data dari hasil pengukuran konsentrasi belajar bermanfaat dalam evaluasi pembelajaran. Namun angket pengukuran konsentrasi belajar sangat terbatas sehingga penelitian mengenai konsentrasi belajar pada mahasiswa sangat sulit. Oleh karena itu, diperlukan angket yang valid untuk mengumpulkan data konsentrasi belajar pada mahasiswa. Studi ini bertujuan untuk melakukan uji validitas angket pada subyek mahasiswa. Metode yang digunakan pada uji validitas ini adalah analitik observasional dengan pendekatan cross sectional. Uji statistik yang digunakan adalah uji korelasi Pearson Product Moment dan uji reabilitas dengan internal consistency. Hasil
\end{abstract}


didapatkan seluruh item pada uji validitas angket di atas 0,3 dan uji reabilitas angket nilai cronbach alpha 0,924. Kesimpulan angket SLCQ-I memenuhi syarat validitas dan reabilitas sehingga dinyatakan valid dan reliabel

Keywords:

Learning Concentration;

SLCQ-I questionnaire;

Validity test;
Coresponden author:

Email: ahmadzidanesagareno@gmail.com

artikel dengan akses terbuka dibawah lisensi CC BY -4.0

\section{Pendahuluan}

Proses pembelajaran di perguruan tinggi yang dijalani mahasiswa merupakan salah satu upaya dalam menjalankan proses untuk memahami ilmu pengetahuan pada berbagai bidang studi. Proses belajar membutuhkan konsentrasi untuk mencapai hasil belajar yang optimal (Brand, 2010; Slameto, 2013). Konsentrasi belajar diasumsikan sebagai tempat untuk menampung ilmu pengetahuan dengan leher yang sempit (Mendoza, Pody, Lee, Kim, \& McDonough, 2018), sehingga diperlukan upaya yang maksimal agar informasi yang disampaikan dapat "masuk", diterima dan dipahami.

Data dari hasil pengukuran konsentrasi belajar akan bermanfaat pada evaluasi pembelajaran di perguruan tinggi. Namun hal tersebut terdapat masalah, yaitu ketersediaan angket yang sangat terbatas, sehingga penelitian mengenai konsentrasi belajar pada mahasiswa tidak mudah untuk dilaksanakan. Angket yang tersedia hanya terbatas pada responden siswa sekolah dasar dan sekolah menengah (sekolah menengah pertama dan/atau sekolah menengah atas). Ketidaksesuaian responden penelitian dengan angket yang tersedia menyebabkan hasil yang ingin dinilai tidak dapat terpenuhi. Berdasarkan permasalahan yang dipaparkan di atas, sangat penting melakukan uji validitas angket konsentrasi belajar mahasiswa. Angket ini merupakan hasil modifikasi dari angket konsentrasi belajar siswa sekolah menengah atas (Chen, Yang, Wu, \& Hsu, 2013).

Hasil modifikasi angket konsentrasi belajar mahasiswa ini ke dalam bahasa Indonesia dengan menyesuaikan responden penelitian. Angket yang dimodifikasi oleh peneliti merupakan angket yang disusun oleh Chen et al. (2013). Angket ini disusun berdasarkan teori konsentrasi yang ditulis oleh Knudsen. Faktor - faktor yang dinilai pada angket ini meliputi salience filter, sensitivity control, competitive selection, dan working memory

\section{Metode}

Metode yang digunakan pada uji validitas ini adalah analitik observasional. Angket yang digunakan peneliti adalah angket konsentrasi belajar Chen et al. (2013) yang dimodifikasi ke dalam bahasa Indonesia dan dilakukan penyesuaian isi angket untuk mahasiswa. Rancanganpenelitian menggunakan pendekatan cross sectional yaitu melakukan pengambilan data hanya satu kali pada satu waktu (Yusuf, 2014). Pilot test diujikan kepada responden di bulan Januari 2020 dengan melibatkan 30 mahasiswa aktif yang sedang menjalani masa pendidikan strata sarjana di Fakultas Kedokteran Malahayati Lampung, kriteria eksklusi yang diterapkan adalah mahasiswa yang pernah mengalami trauma kepala akibat kecelakaan dan/atau yang pernah mendapatkan perawatan kejiwaan akibat gangguan mental psikotik maupun neurotik untuk menghindari hasil bias, karena gangguan mental tersebut dapat menurunkan konsentrasi belajar (Maslim, 2013). Angket SLCQ-I dikirimkan secara online melalui fasilitas google form. 
Angket berisi 19 butir pertanyaan/pernyataan menggunakan skala Likert 1-7. Semua butir pada angket ini favorable. Hasil ukur akan didapatkan skala 19-133, semakin tinggi skor total berarti semakin tinggi konsentrasi belajar. Data dari angket akan diuji validitas dan reabilitas menggunakan aplikasi analisis statistik. Uji validitas yang digunakan adalah uji korelasi Pearson Product Moment dan uji reabilitas dengan internal consistency. Menurut Priyatno (2010) Suatu angket dikatakan valid jika memenuhi syarat $r$ hitung $\geq r$ tabel ( $r$ hitung $\geq 0,3$ ), dan dikatakan reliabel jika nilai cronbach alpha di atas batas acceptable $(a \geq 0,7)$

\section{Hasil Dan Pembahasan}

Dari hasil sampel yang didapatkan didesa Banua Baru dengan jumlah populasi yaitu 38 lansia dari berbagai dusun $(1,2,3,4)$ perempuan maupun laki-laki dengan krtiteria inklusinya usia diatas 60 tahun dengan melakukan pengukuran pengukuran IMT dari lansia didapatkan hasil seperti tabel berikut :

\section{Deskripsi Data Hasil Pilot Test}

Deskripsi Data Hasil Pilot Test disajikan di tabel 1.

Tabel 1. Distribusi Deskripsi Data Hasil Pilot Test Hasil Angket

\begin{tabular}{cccccc}
\hline umlah Responden & Min & Maks & Median & Mean & Standar Deviasi \\
30 & 77 & 127 & 98 & 99,83 & 14,781 \\
\hline
\end{tabular}

Dari tabel di atas dapat diketahui nilai minimum, maksimum, median, mean, dan standar deviasi. Nilai minimum responden pada pilot test ini adalah 71, sedangkan nilai maksimumnya adalah 127. Nilai rata - rata responden 99,83, standar deviasi 14,781.

Tabel 2. Uji Validitas Angket

\begin{tabular}{|c|c|c|c|}
\hline Item Angket & Korelasi & Nilai Batas & Kesimpulan \\
\hline Item 1 & 0,571 & 0,3 & Valid \\
\hline Item 2 & 0,730 & 0,3 & Valid \\
\hline Item 3 & 0,725 & 0,3 & Valid \\
\hline Item 4 & 0,517 & 0,3 & Valid \\
\hline Item 5 & 0,656 & 0,3 & Valid \\
\hline Item 6 & 0,611 & 0,3 & Valid \\
\hline Item 7 & 0,625 & 0,3 & Valid \\
\hline Item 8 & 0,841 & 0,3 & Valid \\
\hline Item 9 & 0,782 & 0,3 & Valid \\
\hline Item 10 & 0,540 & 0,3 & Valid \\
\hline Item 11 & 0,517 & 0,3 & Valid \\
\hline Item 12 & 0,599 & 0,3 & Valid \\
\hline Item 13 & 0,454 & 0,3 & Valid \\
\hline Item 14 & 0,695 & 0,3 & Valid \\
\hline Item 15 & 0.737 & 0,3 & Valid \\
\hline Item 16 & 0,832 & 0,3 & Valid \\
\hline Item 17 & 0,684 & 0,3 & Valid \\
\hline Item 18 & 0,767 & 0,3 & Valid \\
\hline Item 19 & 0,580 & 0,3 & Valid \\
\hline
\end{tabular}

Dari tabel di atas, semua item memiliki korelasi dengan skor total di atas batas valid angket yaitu 0,3 . Nilai 0,3 merupakan batas sebuah item dikatakan valid dengan ketetapan confident interval 95\% dan kesalahan 0,5\% (Priyatno, 2010). 
Tabel 3. Uji Reabilitas Angket

\begin{tabular}{cc}
\hline Cronbach's Alpha & Jumlah Item \\
\hline 0.924 & 19 \\
\hline
\end{tabular}

Dari tabel di atas, nilai cronbach's alpha yaitu 0,924. Nilai tersebut berada di atas batas angket dikatakan reliabel yaitu 0,7 (Priyatno, 2010).

Uji validitas dan reabilitas yang dilakukan peneliti menggunakan responden minimal 30 responden (Priyatno, 2010). Selama pengambilan data, informasi terkait data responden yang bersifat pribadi dipisah dengan pertanyaan pada butir - butir angket, hal tersebut dilakukan agar responden dapat mengemukakan jawaban yang sejujurnya. Jawaban yang masuk ke dalam database selanjutnya dikoding, yaitu transformasi data ke dalam bentuk numerik agar dapat dilakukan analisis statistik. Analisis yang digunakan untuk uji validitas adalah uji korelasi Pearson Product Moment. Uji korelasi dilakukan dengan meng-korelasikan setiap item pada angket dengan skor total. Sebuah angket dinyatakan valid apabila nilai korelasi per-item dengan skor total berada di atas angka 0,3 Pada uji validitas yang telah dilakukan pada 19 item angket menghasilkan seluruh item berada di atas angka 0,3 yang diinterpretasikan bahwa seluruh item pada angket tersebut dinyatakan valid.Pada uji reabilitas, analisis yang digunakan yaitu internal consistency dengan melihat nilai cronbach alpha. Setiap item pertanyaan yang akan dianalisis dimasukkan ke dalam reliability analysis pada aplikasi analisis statistik. Nilai cronbach alpha pada angket harus berada di atas 0,7 agar rebilitas angket tersebut acceptable (Priyatno, 2010; Tavakol \& Dennick, 2011). Pada hasil analisis di atas, uji reabilitas menunjukkan angka 0,924 pada semua item angket, angka tersebut berada di atas angka 0,7 sehingga angket tersebut dinyatakan reliabel. Sebuah angket yang memiliki nilai reabilitas yang baik (di atas 0,7) berarti angket tersebut mampu diandalkan memberikan hasil yang sama dalam pengukuran yang dilakukan berulang ulang (Syahdrajat,

2018).

Dari hasil uji validitas SLCQ-I dapat dilakukan kategorisasi berdasarkan mean dan standar deviasi (Azwar, 2012). Kategorisasi yang digunakan adalah "konsentrasi rendah", "konsentrasi sedang" dan "konsentrasi tinggi". Konsentrasi rendah jika skor total berkisar antara 19-84, konsentrasi sedang jika skor total berkisar antara 85-114, dan konsentrasi tinggi jika skor total berkisar antara 115-133.

\section{Simpulan Dan Saran}

Berdasarkan hasil uji validitas dan reabilitas didapatkan 19 item pada angket dinyatakan valid dan reliabel untuk mengukur skala konsentrasi belajar pada subyek mahasiswa. Angket ini dapat digunakan secara luas dan perlu dikembangkan oleh peneliti selanjutnya dengan memasukkan konsep - konsep baru ke dalam angket berdasarkan teori yang ditemukan

\section{Daftar Rujukan}

Azwar, S. (2012). Penyusunan Skala Psikologi (2nd ed.). Yogyakarta: Pustaka Pelajar.

Brand, L. M. (2010). The Effect of Technology on Attention and Concentration within the Classroom Context. South African Journal of Education, 33(January), 15.

Chen, I., Yang, Y. C., Wu, W., \& Hsu, S. (2013). Development and Evaluation of a Concentration Questionnaire for Students in Classroom. Proceedings of Society for Information Technology \& Teacher Education International Conference 2013, (1), 4226-4230. Maslim, R. (2013). Diagnosis Gangguan Jiwa (2nd ed.). Jakarta: PT Nuh Jaya. 
Mendoza, J. S., Pody, B. C., Lee, S., Kim, M., \& McDonough, I. M. (2018). The Effect of Cellphones on Attention and Learning: The Influences of Time, Distraction, and Nomophobia. Computers in Human Behavior, 86, 52-60.

Elsevier Ltd. Retrieved from https://doi.org/10.1016/i.chb.2018.04.027

Priyatno, D. (2010). Paham Analisis Statistik Data Dengan SPSS. Yogyakarta: Mediakom. Slameto. (2013). Belajar \& Faktor - Faktor Yang Mempengaruhinya. Jakarta: PT Rineka Cipta.

Syahdrajat, T. (2018). Panduan Penelitian Untuk Skripsi Kedokteran \& Kesehatan. Yogyakarta: Pedhe Offset.

Tavakol, M., \& Dennick, R. (2011). Making Sense of Cronbach's Alpha. International journal of medical education, 2, 53-55.

Yusuf, M. (2014). Metode Penelitian Kuantitatif, Kualitatif \& Penelitian Gabungan (4th ed.). Jakarta. 